\title{
APLIKASI METODA GEOMAGNETIK DALAM MENENTUKAN POTENSI SUMBERDAYA BIJIH BESI DI DAERAH BUKIT BAKAR DAN ULU RABAU, KECAMATAN LEMBAH GUMANTI, KAB. SOLOK, SUMATRA BARAT

\author{
Oleh
}

Alanda Idral

Kelompok Program Penelitian Bawah Permukaan, Pusat Sumberdaya Geologi

\section{S A R I}

Daerah Bukit Bakar dan Ulu Rabau, secara administratif termasuk wilayah kenagarian Air Dingin Kec. Lembah Gumanti , Kab. Solok, Sumatra Barat. Data geologi mengindikasikan zona mineralisasi bijih besi pada kedua daerah tersebut diatas terdapat pada batuan meta sedimen dari Formasi Barisan yang berumur Perm. Kedua zona mineralisasi tersebut dikontrol oleh sesar yang berarah baratlaut-tenggara, timurlaut-baratdaya dan timur-barat. Berdasarkan data geomagnetik luas kedua daerah prospek tersebut masing-masing $34960 \mathrm{~m}^{2}$, dan $6914 \mathrm{~m}^{2}$ dengan potensi sumberdaya bujih besi terduga sebesar 2.496.366 ton.

\section{ABSTRACT}

Bukit Bakar and Ulu Rabau area lies in Kenagarian Air Dingin, Kecamatan Lembah Gumanti, Kabupaten Solok, West Sumatra. Based on geological data, both area indicate zones of iron ore mineralization lies in meta-sediment of Barisan Formation of Perm age. The zones are controlled by the NW-SE, NE-SW and E-W fault structures. Based on geomagnetic data the area of both mineralization zones of $34960 \mathrm{~m}^{2}$, and $6914 \mathrm{~m}^{2}$, respectively. The probable potency of the resources of 2.496.366 ton.

Kata kunci: Bukitbakar, Ulurabau, Solok, geomagnetik, anomali, gamma

\section{PENDAHULUAN}

Daerah Bukit Bakar dan Ulu Rabau secara administratif termasuk wilayah Kenagarian Air Dingin, Kec. Lembah Gumanti, Kab. Solok, Sumatra Barat. (Gambar 1).

Penyelidikan geomagnit didaerah tsb, dilakukan dengan menggunakan alat proton unimag geomagnetometer tipe G.856 dengan ketelitian 10 gamma, alat ukur kerentanan magnit batuan dan GPS.

Lintasan ukur geomagnit berjumlah 10 lintasan dengan arah timur - barat memotong struktur sesar yang ada didaerah tsb. Panjang lintasan ukur $600 \mathrm{~m}$, sedangkan titik amat berjumlah 262 titik. Jarak antara lintasan $50 \mathrm{~m}$, dan jarak antara titik amat bervariasi antara 5-50 m. Pengukuran lintasan ukur dan titik ukur dilakukan oleh regu topografi dengan menggunakan alat ukur theodolit

Pengukuran geomagnit dilakukan secara kisi (gridding) dengan sistim tertutup (looping) ABAB.
Nilai intensitas magnit total untuk daerah Solok dan sekitarnya berkisar antara 40.000 gamma - 45.000 gamma ( peta International Geomagnetic Reference Formula), sedangkan nilai intensitas magnit total lokal untuk daerah Air Dingin sebesar 43.060 gamma, selanjutnya, nilai ini, digunakan sebagai nilai 'base stasion'/ back ground untuk daerah tersebut.

Selain itu juga dilakukan pengukuran kerentanan magnit pada beberapa contoh batuan didaerah penyelidikan.

\section{GEOLOGI DAERAH PROSPEK}

Geologi daerah Bukir Bakar dan Ulu Rabau disusun oleh batuan (muda-tua) intrusi granit dan granodiorit yang berumur Kapur; satuan batu gamping (gamping terpualamkan dan gamping meta yang berumur Perm), dan satuan meta-sedimen dari Formasi Barisan yang juga berumur Perm (terdiri dari filit, batusabak dan gamping meta). (Iwan Nursahan, 2004). 


\section{HASIL PENYELIDIKAN GEOMAGNIT}

Dari penyelidikan geomagnit didapat hasil berupa data kerentanan magnit batuan (K), peta anomali geomagnit total sisa dan profil anomali geomagnit total sisa. Penyelidikan geomagnit dilakukan untuk melokalisir zona mineralisasi bijih besi, anomali yang dicari adalah anomaly positif tinggi, dan selanjutnya hanya anomali positif tinggi ini yang akan dibahas, karena biji besi memberikan atau mempunyai nilai kemagnitan positif akibat adanya kandungan mineral magnetit dan ilmenit di dalam batuan.

\subsection{Kerentanan Magnit Batuan}

Kerentanan magnetik batuan didaerah Bukit Bakar dan Ulu Rabau berkisar antara 0.03 $94.0 \times 10^{-6}$ cgs. Nilai $\mathrm{K}$ terendah terdapat pada batuan metasedimen, granit dan gamping, sedangkan yang tertinggi pada bijih besi.

\subsection{Peta Anomali Geomagnit Total Sisa}

Zona anomali geomagnit total sisa didaerah Bukit Bakar-Ulu Rabau dikelompokkan menjadi 3 kelompok anomali (Gambar 2) yaitu:

- Kelompok anomali geomagnit total sisa positif tinggi dengan besaran $>+1000$ gamma, berlokasi pada satuan meta sedimen.

- Kelompok anomali geomagnit total sisa positif sedang dengan besaran 0 (nol) sampai < 1000 gamma, di dominasi batuan granit.

- Kelompok anomali geomagnit total sisa rendah (negatif) dengan besaran/amplitude 0 sampai > negatif 1000 gamma terdapat pada batuan metasedimen dan atau gamping

Secara umum daerah Bukit Bakar-Ulu Rabau didominasi oleh anomali geomagnit total sisa rendah (negatif) dan sedang yang masingmasing menempati bagian selatan dan utara daerah penyelidikan, sedangkan anomali geomagnit total sisa positif tinggi tampak dibagian tengah sekitar lintasan $B$, dan sebelah barat lintasan $\mathrm{J}$, I dan A sampai E, serta sedikit diujung timur lintasan $\mathrm{K}$.

Anomali geomagnetik total sisa positif tinggi, yang mengindikasikan adanya zona mineralisasi bijih besi, tampak di daerah Bukit Bakar dan Ulu Rabau. membentuk kutubkutub positif dengan pola menutup dan dengan nilai + 1000 gamma sampai $>+5000$ gamma .
Sedangkan anomali positif tinggi yang kecil diujung timur utara daerah penyelidikan, diperkirakan merupakan boulder yang mengandung besi kadar rendah, dengan nilai maksimum anomali < 3000 gamma.

\subsection{Penampang Anomali Geomagnit Total Sisa}

Secara umum penampang anomali geomagnit total sisa memperlihatkan anomali positif dengan nilai berkisar antara 0 sampai > 5000 gamma hanya tampak pada titik-titik amat tertentu pada lintasan $A, B, C, D, E, K, J$, dan I, ( Gambar 3).

Anomali geomagnit positif tinggi $(>1000$ gamma) yang tampak di ujung barat lintasan BC-D-E, ditafsirkan berkaitan dengan zona mineralisasi bijih besi.

\subsection{Struktur Sesar}

Struktur sesar sangat erat kaitannya dalam proses terjadinya mineralisasi bijih besi di kedua daerah tersebut diatas, karena zonazona mineralisasi pada umumnya terjadi pada zona struktur sesar/hancuran, karena bidang tersebut merupakan zona yang lemah sehingga memudahkan terjadinya akumulasi bijih besi atau dengan kata lain zona tsb merupakan host rock untuk terjadinya mineralisasi bijih besi. Keterkaitan zona mineralisasi dengan struktur sesar didaerah ini tampak dari hasil penyelidikan geomagnit yang mengindikasikan adanya struktur-struktur sesar didaerah mineralisasi Bukit Bakar dan Ulu Rabau .yang berarah baratlaut - tenggara, timurlautbaratdaya dan hampir timur barat, (lihat Gambar 3.) Keberadaan struktur sesar tersebut selain dari data hasil penyelidikan geomagnit juga didukung oleh kenampakan dilapangan.

\section{Pembahasan}

\subsection{Zona Mineralisasi Bijih Besi dan Struktur Sesar}

Hasil penyelidikan geomanit menunjukkan bahwa zona mineralisasi bijih besi ( $\mathrm{Fe}$ ) ditandai dengan nilai anomali geomagnit positif tinggi > 1000 gamma yang disebabkan oleh kandungan mineral magnetit dan titan didalam batuan. Pada umumnya mineral tersebut mempunyai nilai $\mathrm{K}: 71-94 \times 10^{-6} \mathrm{cgs}$, dan $\%$ Fe total yang relatif tinggi ( $59-69 \%$, Iwan Nursahan 2004). 
Dengan demikian anomali geomagnit tinggi disekitar Bukit Bakar dan Ulu Rabau diperkirakan berkaitan dengan zona mineralisasi bijih besi. Ditemukannya singkapan batuan yang insitu dan endapan besi deluvial pada kedua lokasi tersebut diatas juga merupakan suatu indikasi permukaan/data pendukung untuk keberadaan zona mineralisasi bijih besi didaerah Bukit Bakar dan Ulu Rabau.

Dari data geomagnetik diduga luas daerah mineralisasi bijih besi di Bukit Bakar $34960 \mathrm{~m}^{2}$ , memanjang dari baratlaut ke tenggara, mulai dari lintasan $\mathrm{J}$ sekitar titik amat J-300 dan menerus kearah tenggara sampai lintasan E sekitar titik amat E 500. Zona mineralisasi tersebut terdapat antara perpotongan dua struktur sesar yang berarah baratlaut-tenggara dan hampir utara-selatan, dengan demikian daerah tersebut merupakan zona hancuran, sehingga memungkinkan untuk terjadinya mineralisasi bijih. Keberadaan zona hancuran tersebut ditandai dengan adanya bijih besi deluvial disekitar daerah mineralisasi. Hal ini menunjukkan bahwa struktur sesar cukup berperan dalam proses pembentukan zona mineralisasi bijih besi didaerah Bukit Bakar. Zona mineralisasi Bukit Bakar berada pada zona anomali geomagnetik positif tinggi 1000 gamma sampai $>+6000$ gamma, sedangkan nilai $\mathrm{K}$ berkisar antara $71-94 \times 10^{-6} \mathrm{cgs}$, dan Fe total 62-69 \%.

Berdasarkan data geomagnetik mineralisasi bijih besi di Ulu Rabau, terdapat di timur Bukit Bakar, membentuk seperti lensa, dengan luas $6914 \mathrm{~m}^{2}$, terkonsentrasi pada lintasan B sekitar titik amat B 600 - B 800, zona tersebut ditandai dengan pola anomali menutup > 1000 gamma sampai 2800 gamma, nilai kerentanan magnit, $\mathrm{K}=20 \times 10^{-6} \mathrm{cgs}$, dan Fe total $59 \%$. Relatif kecil luas zona mineralisasi dan rendahnya nilai anomali geomagnetik di Ulu Rabau bila dibandingkan dengan Bukit Bakar diperkirakan erat kaitannya dengan keberadaan struktur sesar yang berkembang didaerah ini. Data geomagnetic mengindikasikan daerah mineralisasi Ulu Rabau hanya dilalui oleh struktur sesar yang berarah baratlaut-tenggara, sedangkan sesar berarah timur-barat (data geologi) tidak ada indikasi dari data geomagnetik.

Anomali positif tinggi disekitar titik amat K-850 dengan zona anomali relatif kecil (dibandingkan dengan Bukit Bakar dan Ulu Rabau), diperkirakan berkaitan dengan boulder yang mengandung mineral besi kadar rendah.

\subsection{Pemodelan Anomali Geomagnit Total Sisa 2 D}

Model anomali geomagnit total sisa $2 \mathrm{D}$ dilakukan melalui penampang $A B$, dan $C D$ dengan menggunakan program grav and mag tipe 3.1

Penampang AB (Gambar 4) dibuat dengan arah hampir utara selatan, memotong zona mineralisasi bijih Bukit Bakar. Penampang $A B$ memperlihatkan bentuk tonjolan anomali positif yang dominan dan anomali negatif hanya tampak diujung kanan (timur) penampang. Kontras yang besar antara anomali positif dan negatif pada ujung kanan penampang $A B$ ( > 10000 gamma) mencirikan adanya struktur sesar didaerah tersebut. Model 2D penampang bawah permukaan $A B$ memperlihatkan zona mineralisasi berbentuk lensa dengan panjang +/-400 $\mathrm{m}$ dan tebal ratarata $10 \mathrm{~m}$. Kontras $\mathrm{K}$ untuk daerah Bukit Bakar sebesar $0.62 \times 10^{-6} \mathrm{cgs}$.

Penampang C-D (Gambar 5), memotong zona mineralisasi Ulu Rabau dengan arah hampir utara selatan. Penampang ini memperlihatkan tonjolan anomali positif yang relatif kecil baik nilainya maupun dimensinya bila dibandingkan dengan mineralisasi Bukit Bakar, Zona mineralisasi didaerah ini memperlihatkan bentuk sill yang tak beraturan dan terdapat sampai kedalaman kurang dari 30 $\mathrm{m}$ dengan ketebalan maksimum $10 \mathrm{~m}$ dan minimum $4 \mathrm{~m}$.

\subsection{Sumber daya}

Berdasarkan data geomagnetik dan hasil uji analisis laboratorium fisika mineral besarnya sumber daya terduga bijh besi dengan densiti $5.1 \mathrm{~kg} / \mathrm{cm}^{3}$, pada masing-masing daerah adalah sebagai berikut:

- Bukit Bakar sumber daya terduga sekitar 1.689.733 ton bijih.

- Ulu Rabau sumberdaya terduga sekitar 806.633 ton bijih ,

\section{SIMPULAN}

Luas daerah mineralisasi bijih besi, di Bukit Bakar $43.960 \mathrm{~m}^{2}$, dan Ulu Rabau $6.914 \mathrm{~m}^{2}$.

Beberapa faktor yang berperan penting dalam proses pembentukan mineralisasi bijih besi di didaerah penyelidikan antara lain keberadan struktur sesar, dan batuan induknya. Besarnya nilai kerentanan magnetik batuan, persentase Fe total merupakan indikasi yang baik dalam 
mengaplikasikan metoda geomagnetik. Aplikasi metoda geomagnit dalam menentukan keberadaan sumberdaya bijih besi didaerah penyelidikan memberikan hasil yang baik dengan kontras yang besar antara daerah mineralisasi dan bukan mineralisasi

Sumberdaya terduga bijih besi pada kedua daerah tersebut diatas diperkirakan sebesar 2.496.366 ton bijih besi.

\section{UCAPAN TERIMA KASIH.}

Ucapan terima kasih disampaikan kepada pada rekan-rekan atas masukan dan sarannya, editor atas koreksinya dan PMG untuk diterbitkannya makalah ini.

\section{DAFTAR PUSTAKA}

A Idral; dkk, 1992: Penyelidikan geofisika terpadu untuk mineralisasi sulfida di daerah Pandeglang, Jawa Barat, DSM, Bandung,Tidak diterbitkan

ral; dkk; 1995 : Penyelidikan geofisika terpadu untuk mineralisasi sulfida di daerah CikonengCibaliung, kab. Pandeglang, Jabar; D.S.M; Bandung. Tidak diterbitkan

Empon Ruswandi, dkk; 1986: Penyelidikan geofisika di daerah Bukit Raya, kec. Rawas Ulu, Kkab. Musi Rawas, Propinsi Sumsel. D.S.M. Bandung. Tidak diterbitkan.

Iwan Nursahan, (2004): Geologi Daerah Air Abu dan sekitarnya. Tidak diterbitkan

Parasnis, D.S., 1979: Principles of Applied Geophysics,Chapman and Hall, p.4-56.

Sumantri, M; Idral, A. ,Pohan, M.P; 1980: Penyelidikan geofisika terpadu untuk mineralisasi sulfida di daerah Masurung - Kaputusan P. Bacan, Maluku, DSM, Bandung. Tidak diterbitkan

Telford, W.M. et al, 1982. Applied Geophysics. Cambridge University Press. Cambridge p.105-216. 


\section{MAKALAH ILMIAH}

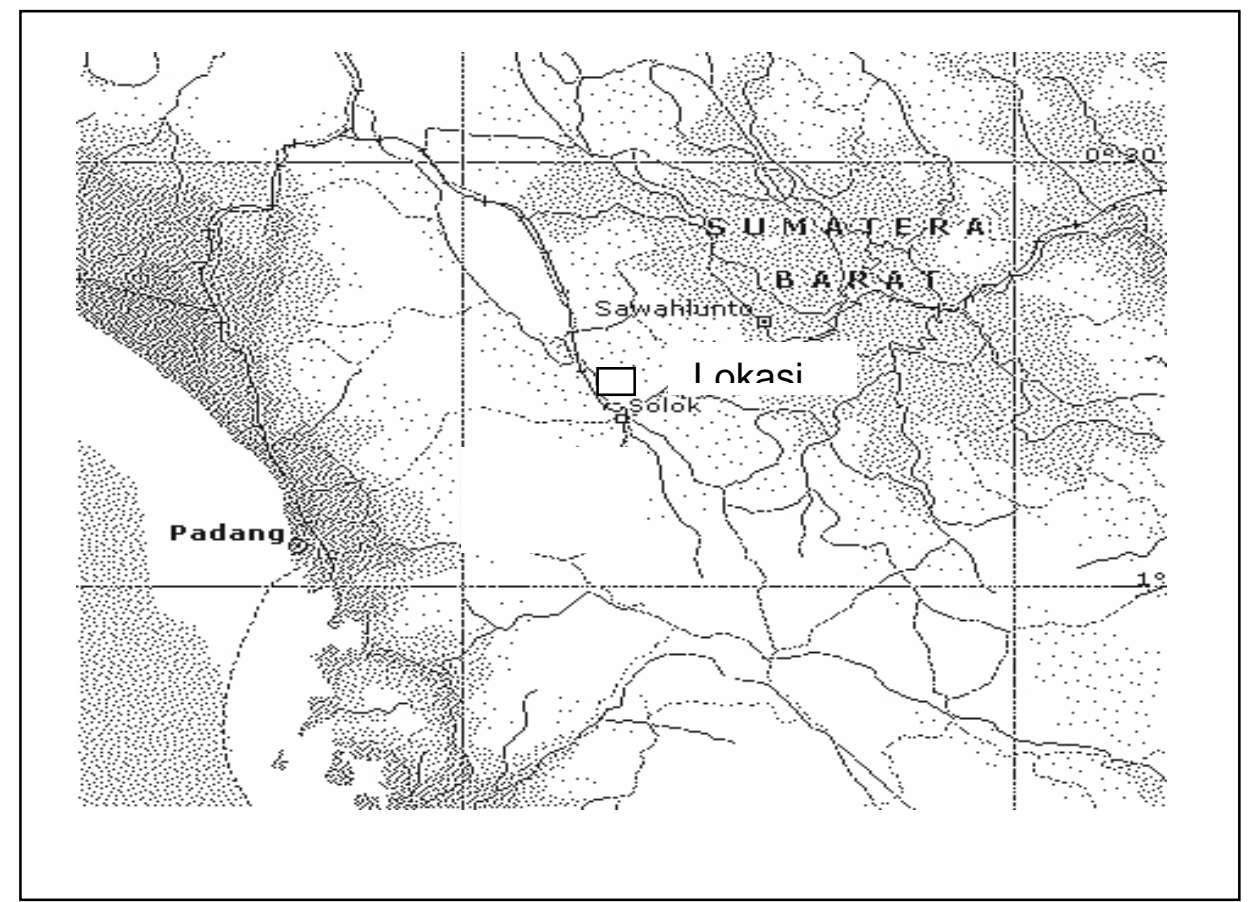

Gambar 1. Lokasi daerah prospek

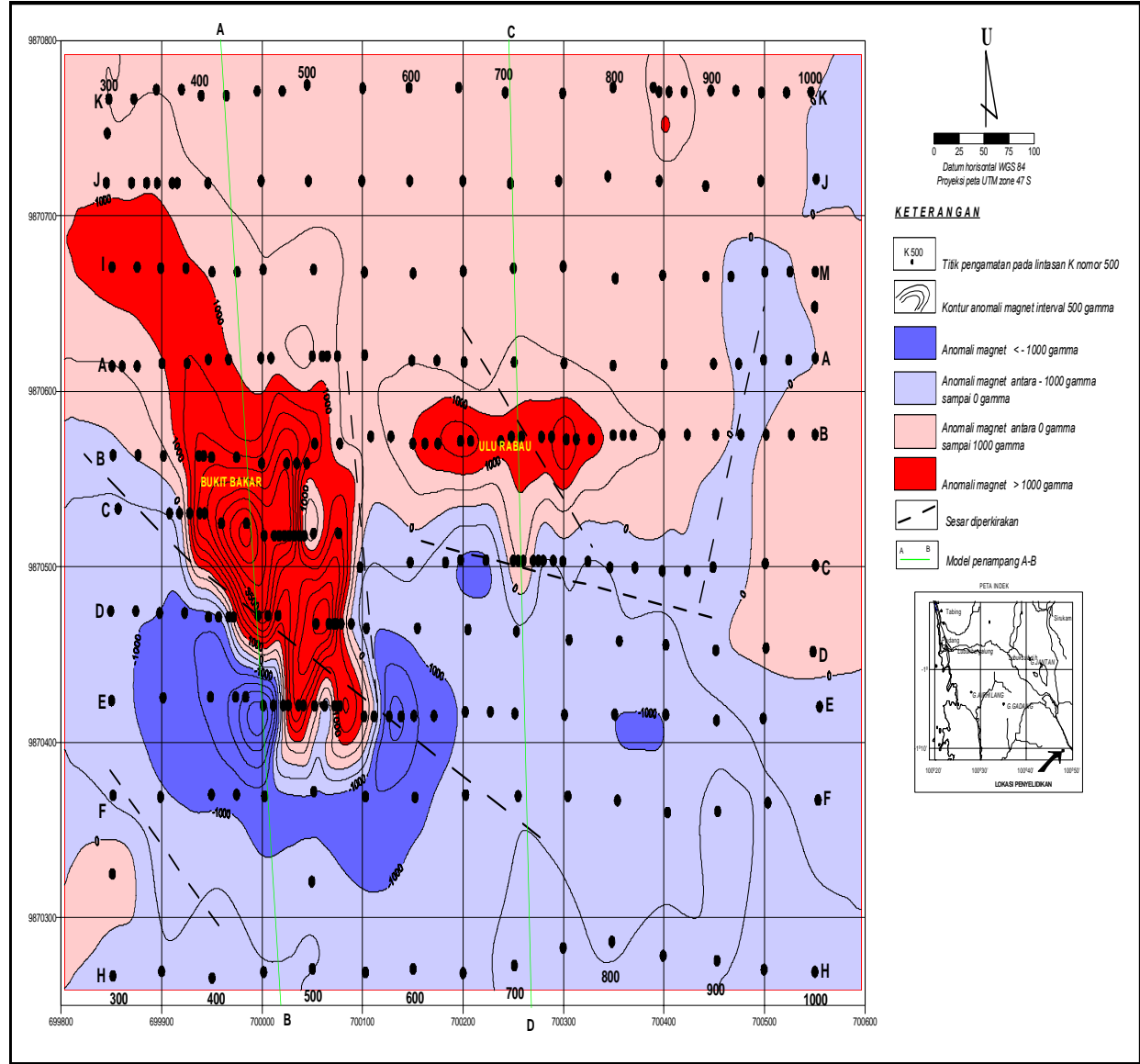

Gambar 2. Peta anomali geomagnit 


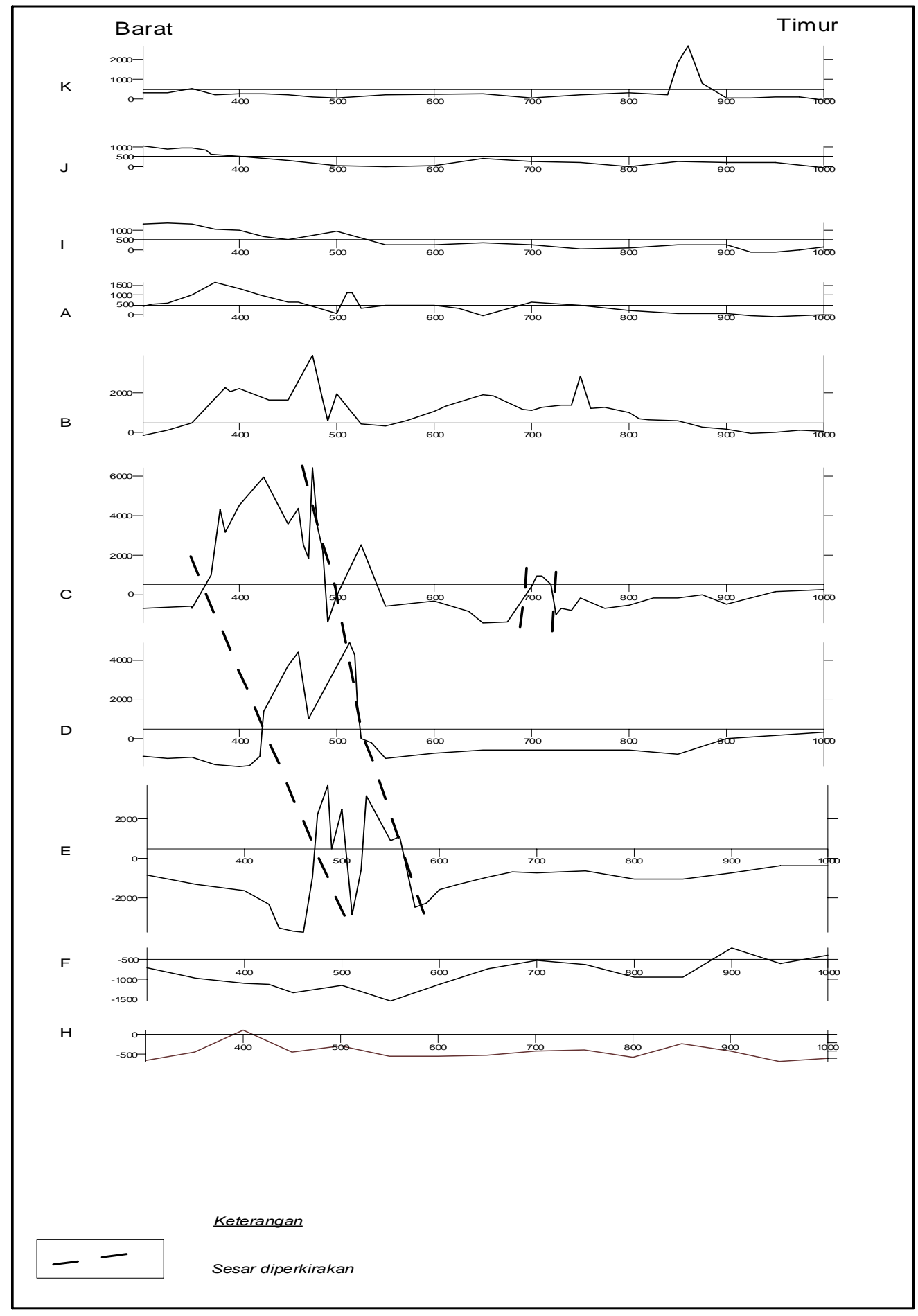

Gambar 3. Penampang anomali geomagnit Bukit Bakar 


\section{MAKALAH ILMIAH}

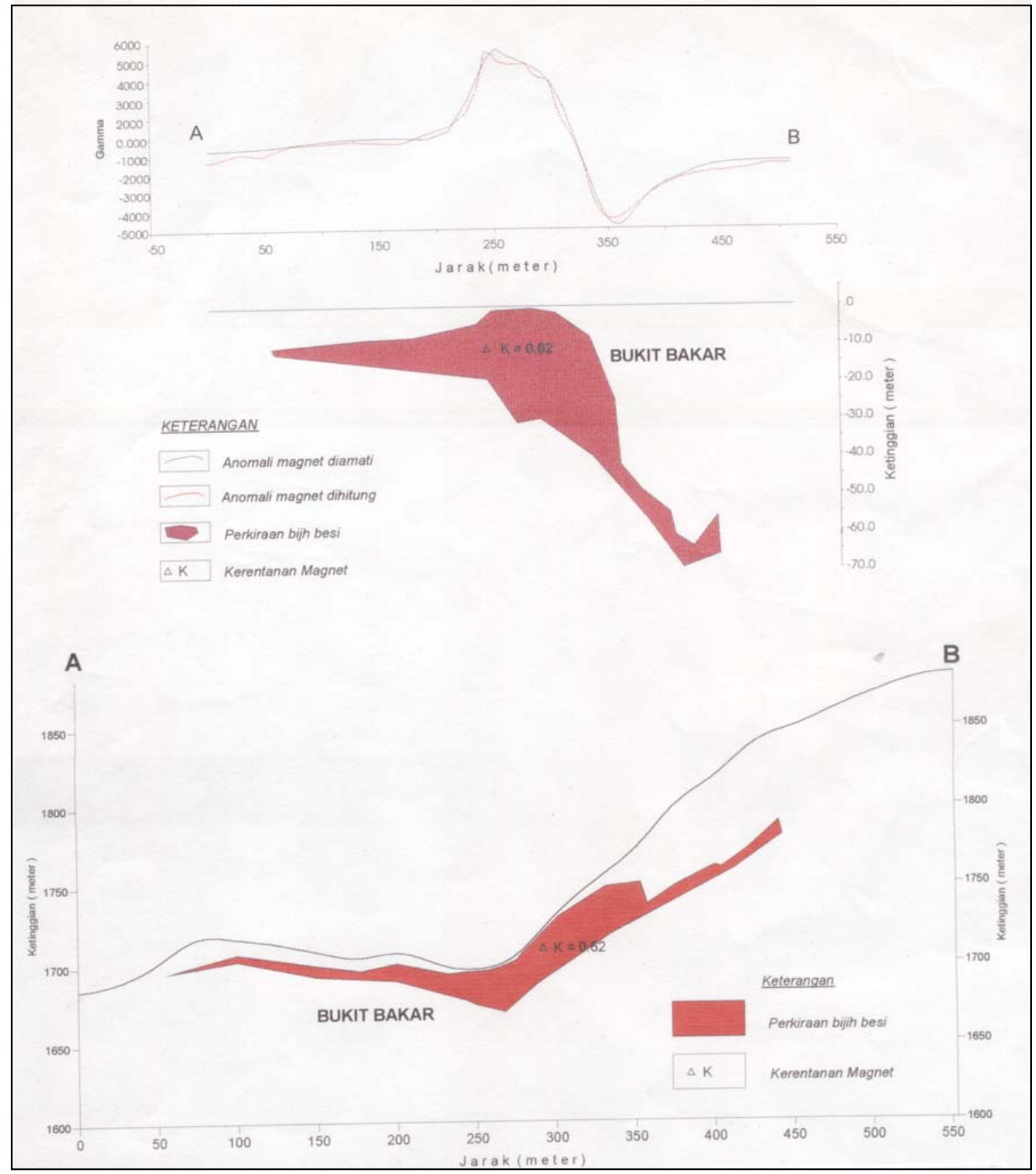

Gambar 4. Model 2-D anomali geomagnit Bukit Bakar 


\section{MAKALAH ILMIAH}
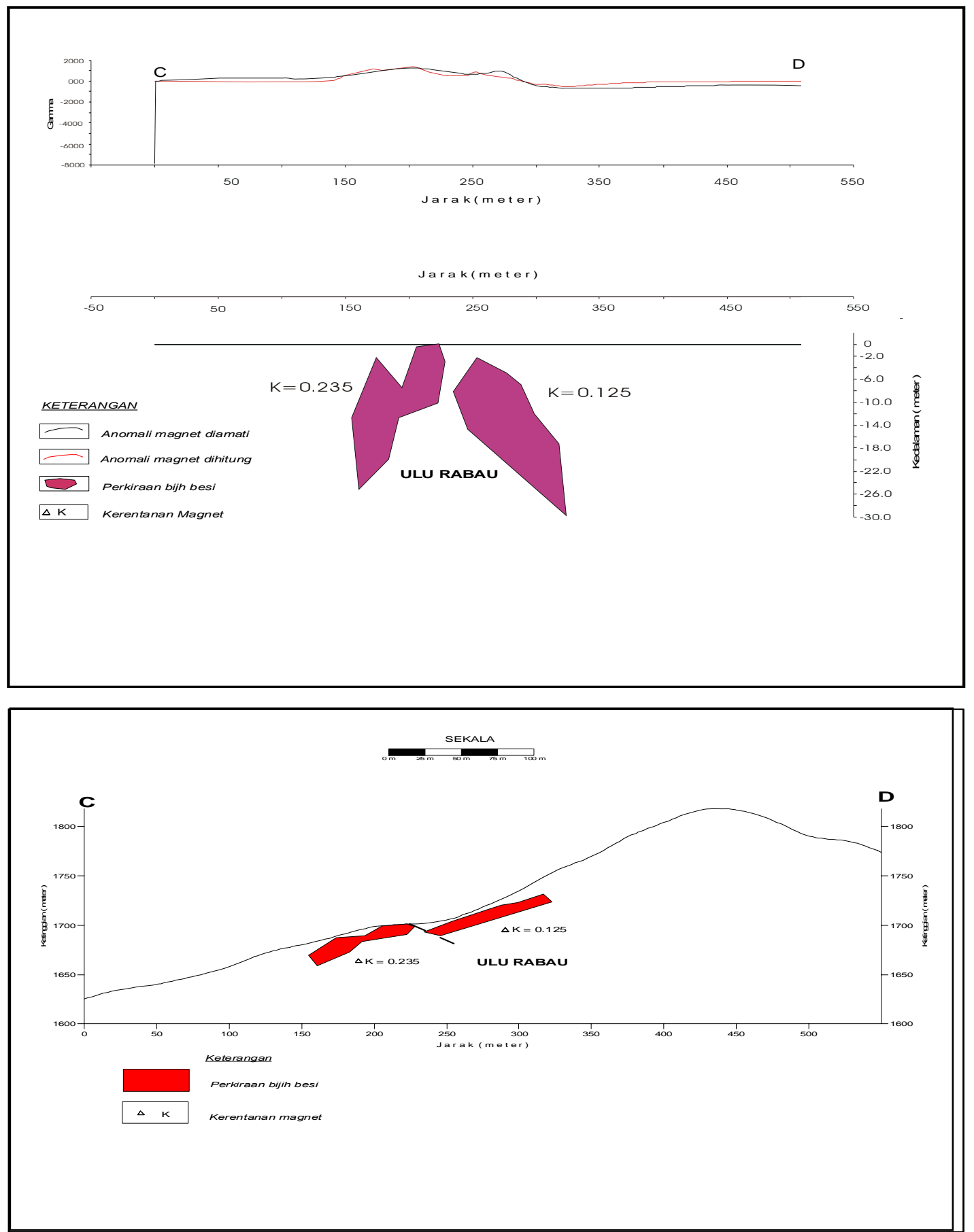

Gambar 5. Model 2-D anomali geomagnet UluRabau 